\title{
Electrochemical Characterization of Amoxycillin, a Broad Spectrum Antibiotic on a Bentonite Host Matrix, Using Cyclic Voltammetry
}

\author{
Duke Orata $^{* 1}$, Yusuf Amir ${ }^{1}$, Claire Nineza ${ }^{2}$, Marina Mukabi ${ }^{1}$ \\ 1-Department OfChemistry, University Of NairobiP.O. Box 30197-00100, Nairobi \\ 2- University Of Burundi Bujumbura
}

\begin{abstract}
In this paper we report on the redox properties of amoxycillin, a broad spectrum anti biotic. on a bentonite modified working electrode. The CV obtained with ethanol is well defined and quasi reversible suggesting fast electrode kinetics. The oxidation peak in the case of water exhibits a shoulder at $0.195 \mathrm{v}$ and a well defined peak at $0.465 \mathrm{v}$ with a broad reduction peak approximated at $0.450 \mathrm{v}$. In the case of ethanol, there is a single well defined oxidation peak at $0.480 \mathrm{v}$ and a well defined reduction peak at $0.330 \mathrm{v}$.

Interaction of amoxycillin with metal cations $\left(\mathrm{co}^{2+}, \mathrm{pb} \mathrm{b}^{2+}, \mathrm{fe}^{2+} \mathrm{cu}^{2+}\right)$, amino acids- methionine, leucine arginine and with hydrocortisone and paracetamol was assessed. The results obtained confirm the interactions of amoxil with these chemical substances. The amoxil redox potential is altered or inhibited in certain cases. This is informative given that these substances are commonly used together with amoxil as part of a prescription, notwithstanding the fact that the amino acids are iimportant macromolecules in the human biochemical/physiological system.

The UV-vis spectrophotometric analysis showed that, the absorbance of amoxil is a affected by electrolyte solution $\mathrm{pH}$, probably an indication of the latter affecting the extent of conjugation in amoxil.

key words:amoxycillin (amoxil), antibiotic, bentonite, cyclic voltammetry
\end{abstract}

\section{Introduction}

Amoxil is a popular anti-biotic used globally as a broad spectrum antibiotic. The formulations of amoxil contain amoxycillin an analog of ampicillin. this broad spectrum antibiotic is effective against many gram-positive and gram negative micro-organisms. The chemical structure of amoxil is shown below in figure 1 .

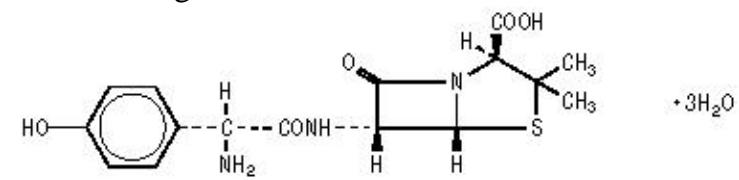

Figure 1: Chemical Structure Of Amoxil.

Amoxil Chemical Structure In The IUPAC Notation Is (2S,5R,6R)-6-[(R)-(-)-2-Amino-2-(PHydroxyphenyl)Acetamido]-3,3-Dimethyl-7-Oxo-4- Thia-1-Azabicyclo[3.2.0]Heptane-2-Carboxylic Acid Trihydrate.

The molecular weight of amoxicillin is 419.45 and the molecular formula is $\mathrm{C}_{16} \mathrm{H}_{19} \mathrm{~N}_{3} \mathrm{O}_{5} \mathrm{~S} \cdot 3 \mathrm{H}_{2} \mathrm{O}$.

There has been significant electrochemical research in attempts to understand the redox properties of macromolecules. Surface modified electrodes have not featured prominently in these studies. references 1-14, and references therein.

In this paper, we report on the redox activity of amoxil on a bentonite modified carbon graphite working electrode.

Cyclic voltammetry has been used in the electro-analysis of amoxil and uv spectrophotometry used to assess its chromic properties.

\section{Experimental section}

Pharmaceutical grade amoxycillin powder and $500 \mathrm{mg}$ amoxil tablets (Smithkline Beecham) were used as received. In the case of the prescription drugs purchased from local reputable chemists, the encapsulation was removed and the powder therein used in the electro-analysis without further purification.

All the acids and solvents were used as received without further purification. All solutions were prepared using triply distilled water or de-ionised water from a millipore purification system.

The cyclic voltammograms were generated using PAR173 potentiostat/galvanostatused in conjunction with the PAR 175 universal programmer. The out-put signal was fed into a PAR $189 \mathrm{X}$-Y recorder. 
The UV spectrophotometer used was Bausch lamb model.

\section{Effect Of Solvent}

\section{Results And Discussion:}

We commenced our electro-analysis by studying the effect of solvent on amoxil. The latter was immobilized on bentonite by forming a slurry separately with water and ethanol. The carbon graphite working electrode surface was then modified using the amoxil containing bentonite. The purpose of immobilization on a clay montmorillonite was to preconcentrate the amoxil (1) and hence enhance the electrochemical signal when these combinations are used in bulk solution.

The potential of the working electrode was then cycled from $-0.4 \mathrm{v}$ to $0.8 \mathrm{v}$ at a scan rate of $20 \mathrm{mv} / \mathrm{sec}$. The resultant cyclic voltammetric responses are shown in Figures $2 \mathrm{a}$ and $2 \mathrm{~b}$.

Fig.2a
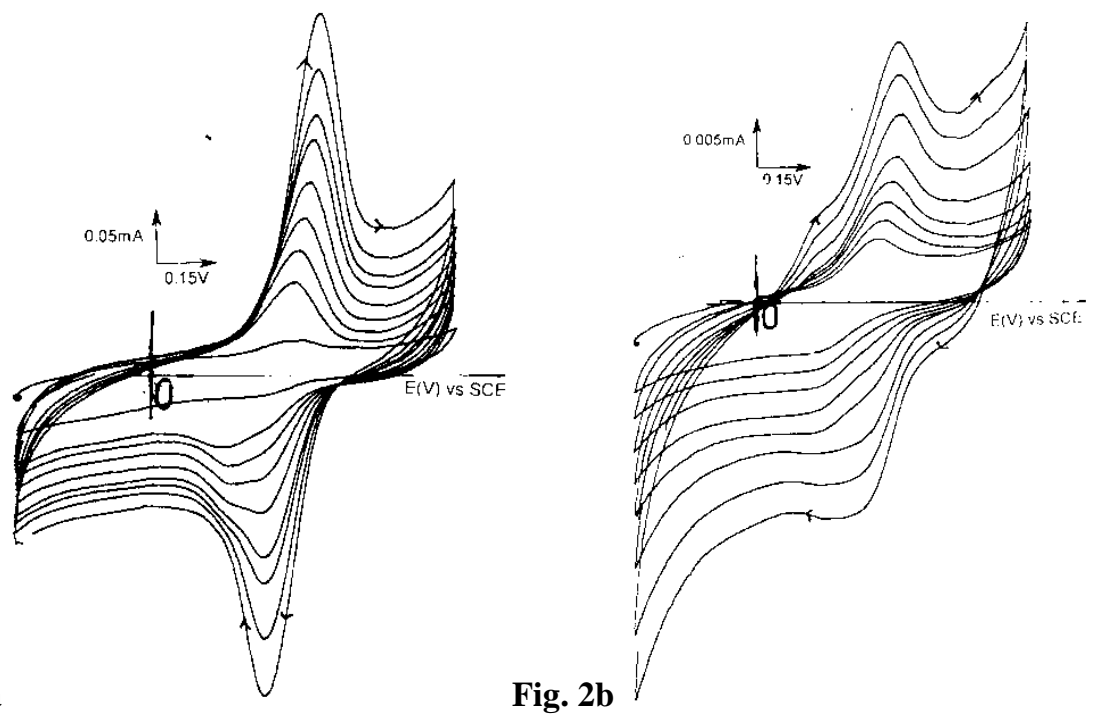

Fig. $2 b$

Figure2a: - CV ForAmoxil In Ethanol.

Figure 2b: CV Obtained For Amoxil In Water.

The cyclic voltammograms for the two solvents are very different. The CV obtained with ethanol is well defined and quasi reversible suggesting fast electrode kinetics. The oxidation peak in the case of water exhibits a shoulder at $0.195 \mathrm{v}$ and a well defined peak at $0.465 \mathrm{v}$ with a broad reduction peak approximated tangentially at $0.450 \mathrm{v}$. In the case of ethanol, there is a single well defined oxidation peak at $0.480 \mathrm{v}$ and a well defined reduction peak at $0.330 \mathrm{v}$. The rate of change of anodic peak current $\left(i_{\text {pa }}\right.$ is higher in water than in ethanol (see Figures $3 a$ and $3 b$ ).
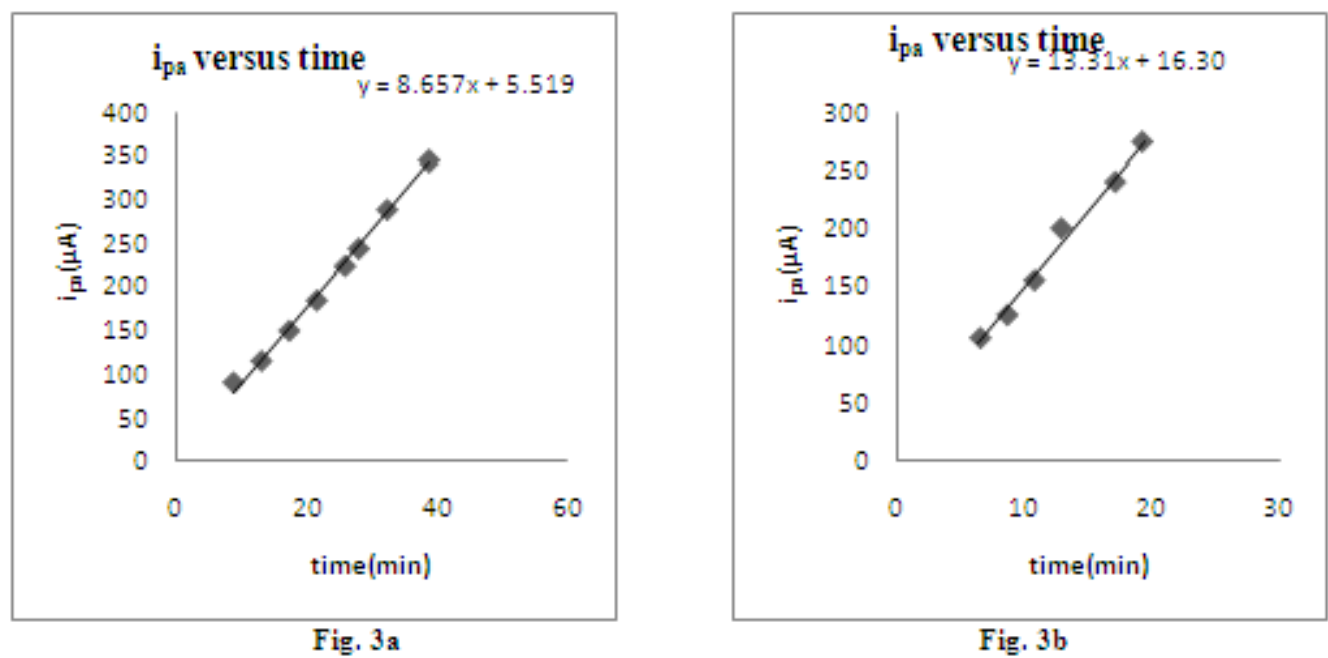

Figures $3 \mathrm{a}$ and $3 \mathrm{~b}$ : IPA versus time for amoxil in ethanol and in water respectively. 
These differences can be attributed to the solubility of amoxil in the two solvents i.e., solubility higher in water than in ethanol.

It is also worth noting that, despite the differences in the cyclic voltammetric profile for the ethanol and water cases, the redox potentials were not affected. This is a strong pointer to the fact that, the configuration/or structural integrity of the amoxil in the bentonite host matrix is not affected by solvent type. If this was not the case, then from entropic considerations we would have expected to observe a change in the redox potentials.

The scan rate dependence studies profiles yielded linear plots for anodic peak current versus scan rate irrespective of the solvent used.

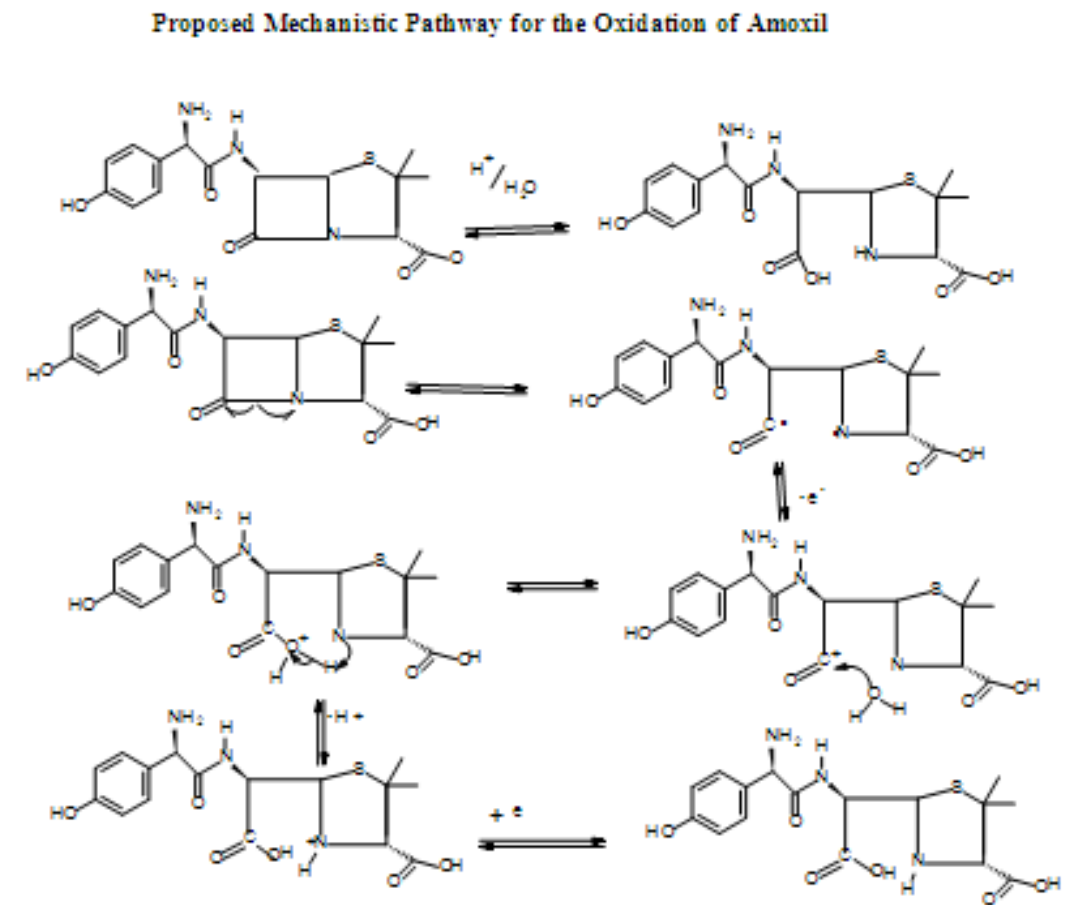

\section{Scheme 1: Proposed Scheme Of The Oxidation/Reduction Of Amoxicillin}

Amoxil has an amide functional group which is electrochemically close to Azetidine-2-one functionality. Therefore it is expected to undergo hydrolysis with opening of the four membered Azetidine-2one ring, in a $2 \mathrm{H}^{+} / 1 \overline{\mathrm{e}}$ process. This redox behavior closely resembles the quinine/imine redox process in polynaline (2)

\section{Effect Of Metal Ions On Amoxil Redox Activity}

In the study on the effect of metal cations on amoxil, the bentonite host matrix used in the modification of the working electrode was prepared by mixing amoxil, bentonite and metal ions in the ratio by mass of 1: 1 : 0.1 . The metal cations were $\mathrm{Cu}^{2+}, \mathrm{Fe}^{2+} / \mathrm{Fe}^{3+}, \mathrm{Pb}^{2+}$, and $\mathrm{Co}^{2+}$. The analysis was done in $1 \mathrm{~m}_{2} \mathrm{SO}_{4}$ as supporting electrolyte and the potential was cycled from $-0.4 \mathrm{v}$ to $0.9 \mathrm{v}$ at a scan rate of $20 \mathrm{mv} / \mathrm{sec}$.

\section{Copper (II) Ion}

The cyclic voltammetric response in the case of $\mathrm{Cu}^{2+}$, (see Figure 4a), yielded two oxidation peaks at $0.15 \mathrm{v}$ and $0.330 \mathrm{v}$ and a reduction characterized by a peak at $0.360 \mathrm{v}$, a shoulder at $-0.030 \mathrm{v}$ and a well defined peak at $-0.225 \mathrm{v}$. 


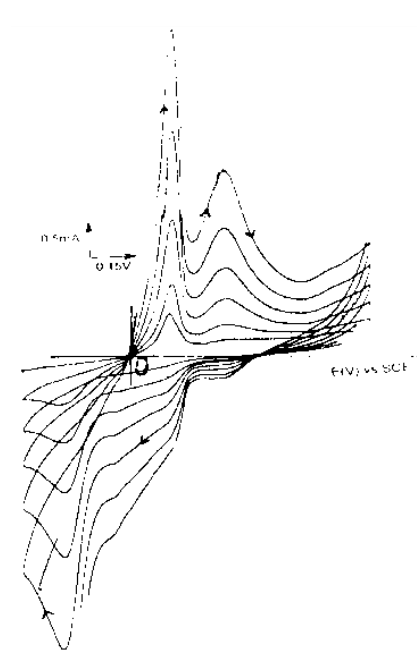

Figure 4a: CV Response Obtained In The Case Of Amoxil/Bentonite/Cu ${ }^{2+}$ Modified Electrode

The peaks at $0.15 \mathrm{v} /-0.225 \mathrm{v}$ and $0.330 \mathrm{v} / 0.360 \mathrm{v}$ represent the peak of $\mathrm{Cu}^{2+}$ oxidation/reduction peak of $\mathrm{Cu}^{2+}$ process and for amoxil respectively. The amoxil oxidation potential occurred at $0.330 \mathrm{v}$ as opposed of $0.450 \mathrm{v}$ in the absence of $\mathrm{Cu}^{2+}$. This suggests that $\mathrm{cu}^{2+}$ electro-catalyzes the amoxil redox significantly lowering its oxidation potential by $120 \mathrm{mv}$. We proposed that, this is as a result of possible interaction between their redox centres/spheres. It is also worth noting that, the cyclic voltammograms are very sharp suggesting an efficient faradaic process (fast electron transfer kinetics)/ and or significant changes in the solvent content/population in the host matrix.

The rates of change of $\mathrm{i}_{\mathrm{pa}}$ for the two redox centers are shown in Figures $5 \mathrm{a}$ and $5 \mathrm{~b}$.

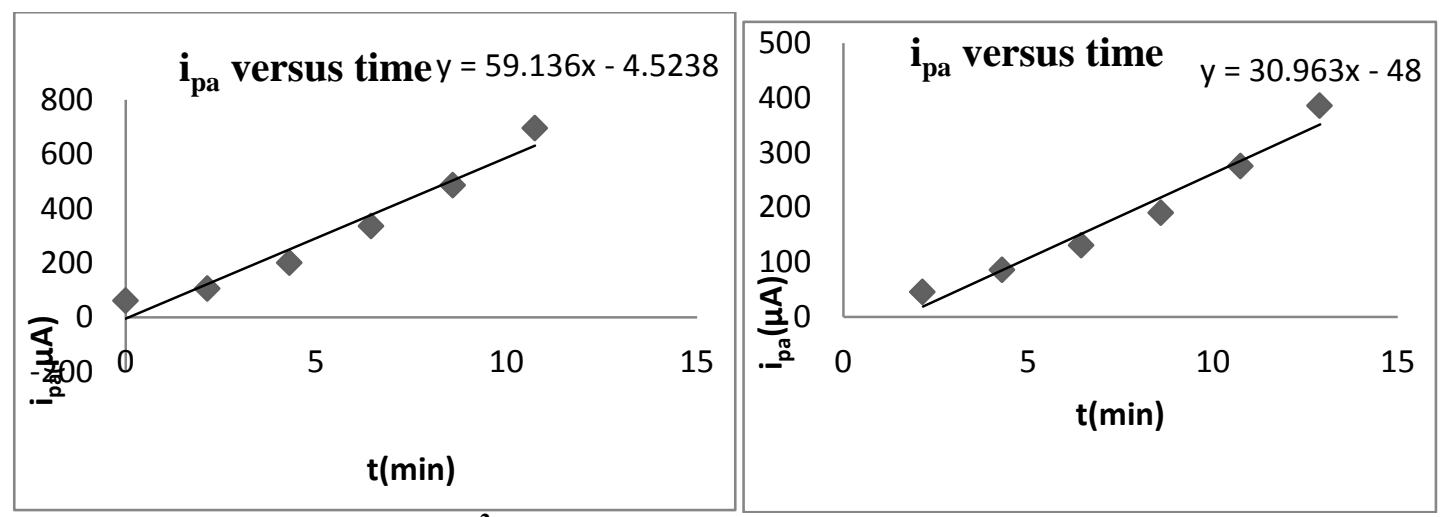

Fig. 5a: $\mathbf{I}_{\mathrm{pa}}$ Versus Time For $\mathrm{Cu}^{2+}$ Figure 5b: $\mathbf{I}_{\mathrm{pa}}$ Versus Time For Amoxil

The reduction peak of amoxil at $0.330 \mathrm{v}$ is significantly suppressed as compared to the response on bentonite modified electrode. We observe that, the oxidative charge in $\mathrm{Cu}^{2+}$ is much greater than its corresponding reductive charge. This shows that the electrocatalytic activity of $\mathrm{Cu}^{2+}$ mimics its redox profile. Therefore, it is possible that, the presence of $\mathrm{cu}^{2+}$ in the same system with amoxil will enhance its therapeutic activity assuming that the latter is a function its redox activity. This assertion remains purely speculative.

\section{Lead II Ion}

When the same analysis was repeated using $\mathrm{Pb}^{2+}$ in the place of $\mathrm{Cu}^{2+}$, the cyclic voltammogram obtained is shown in Figure 6. A well defined quasi reversible redox process was obtained, with the oxidation and reduction peaks occurring at $0.525 \mathrm{v}$ and $0.330 \mathrm{v}$ respectively. The redox efficiency of the redox process is $84.1 \%$ as obtained from the correlation coefficient (3) obtained from the plot of $i_{p c}$ versusi $i_{p a}$ (see Figure 7). 

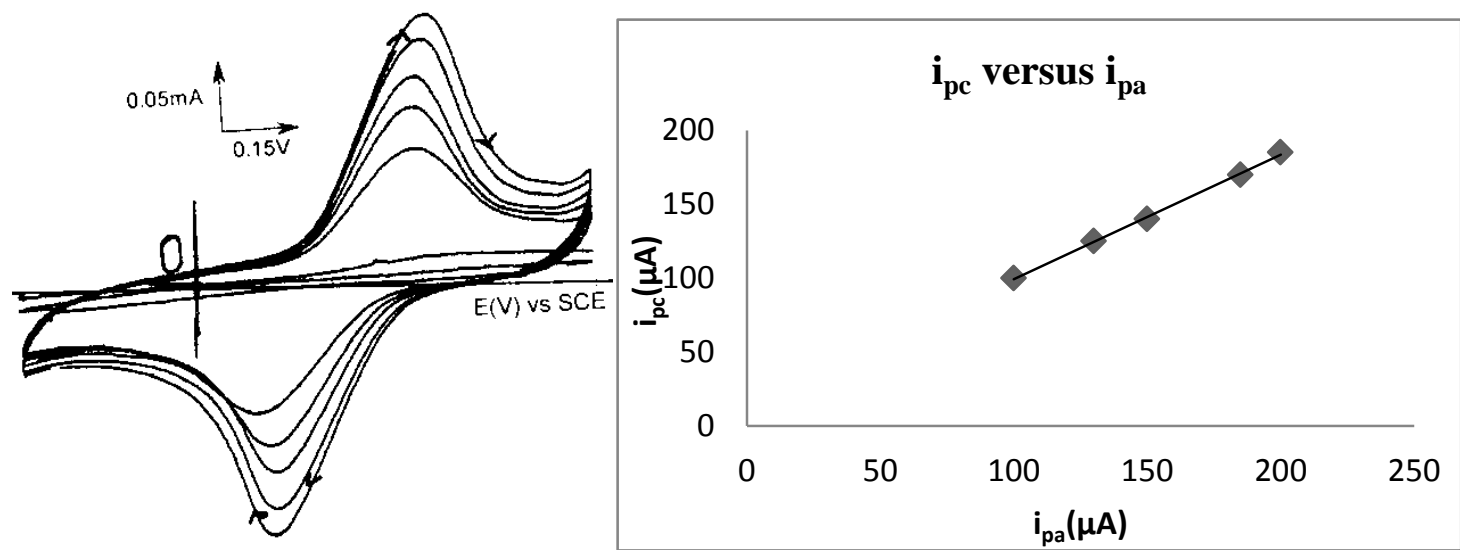

Fig. 6: CV Responses Obtained In The Case Of Amoxil/Bentonite/ $\mathbf{P b}^{2+}$ Modified Electrode Fig. 7: $\mathbf{I}_{\mathrm{pc}}$ versusI $\mathbf{I}_{\mathrm{pa}}$ In The Case Of Amoxil/Bentonite/ $\mathbf{P b}^{2+}$ Modified Electrode

The efficiency of the process is relatively low (84\%), suggesting that for every incremental increase in the oxidative peak, there is no corresponding increase in the reduction peak.

It is interesting to note that the $\mathrm{Pb}^{2+}$ redox center is not observed but there is a positive shift in the oxidative potential of approximately $38 \mathrm{mv}$ and a negative shift in the reduction potential of approximately $130 \mathrm{mv}$. This observation suggests that, the interaction of the lead and amoxil oxidative centres is not in consonance with the interaction of their reductive centres. This further suggests that, these interactions affects the gibbs free energy associated with amoxil unequally. The presence of $\mathrm{pb}^{2+}$ therefore can significantly alter the redox action of amoxil, wether this kind of interaction will be observed in a physiological system containing amoxil and lead, once again remains purely speculative.

\section{Iron III}

Ithe case of amoxil/bentonite/ $\mathrm{Fe}^{3+}$ modified electrode, the cyclic voltammogram obtained is shown in Figure 8 . The oxidation peak is observed at $0.525 \mathrm{v}$ with a double humped reduction peak occurring at $0 \mathrm{~V}$ and

$0.270 \mathrm{~V}$.

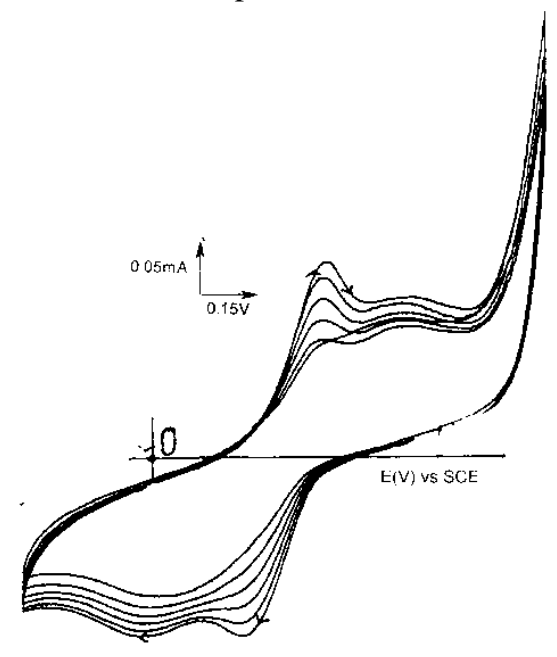

\section{Figure 8: CV Response Obtained In The Case Of Amoxil/Bentonite/ $\mathbf{F e}^{3+}$ Modified Electrode}

the oxidation peak at $0.525 \mathrm{v}$ and reduction peak at $0.270 \mathrm{v}$ can be assigned to amoxil redox activity. From the redox profile it is apparent that $\mathrm{Fe}^{3+}$ does not significantly alter the redox activity of amoxil compared to $\mathrm{Cu}^{2+}$ and $\mathrm{Pb}^{2+}$. If this observation can be reproduced at the physiological level, then the import is that, an anaemic patient on iron prescription, can use safely use amoxil simultaneously.

\section{Cobalt II Ion}

The presence of $\mathrm{Co}^{2+}$ in the bentonite/amoxil host matrix yielded very poorly defined voltammograms pointing to inhibitory tendencies of the $\mathrm{co}^{2+}$ on the amoxil redox activity. See Figure 9. 


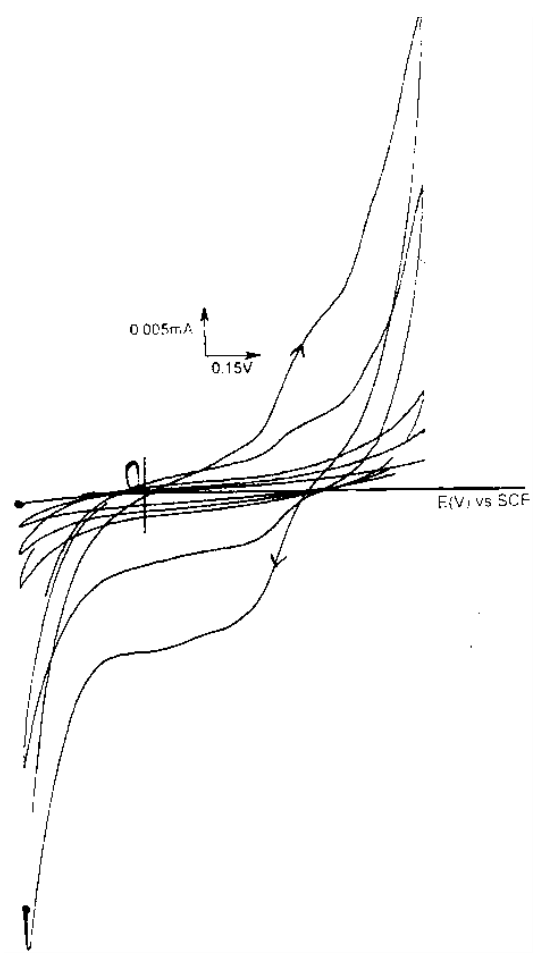

Figure 9: CV Responses Obtained In The Case Of Amoxil/Bentonite/ $\mathrm{Co}^{2+}$ Modified Electrode

It is difficult to speculate exactly on how $\mathrm{Co}^{2+}$ inhibits the action of amoxil given that $\mathrm{Co}^{2+}$ is a transition metal with strong complexation tendancies to form an octahedral structure, unlike $\mathrm{Cu}^{2+}$ which is characterized by distortion. Since the bentonite is a clay montmorillonite with tetrahedral and octahedral sites, it is not surprising that the $\mathrm{Co}^{2+}$ will undergo isomorphous substitution occupying the octahedral sites in bentonite and hence will form very stable complexes with the ligand. This stability can compromise or totally suppress the redox activity of the amoxil given the decrease in entropy.

\section{Effect of some Amino-Acids on Amoxil Redox Activity in Water and Ethanol}

Amino acids are important building blocks in proteins, a very important macro-molecule in humans.

The amino acids were mixed with bentonite, amoxil and water/ethanol mixture to form slurry for use in the modification of the working electrode surface. the resultant cyclic volatmmetric responses are shown in figures 10(a)-(f).
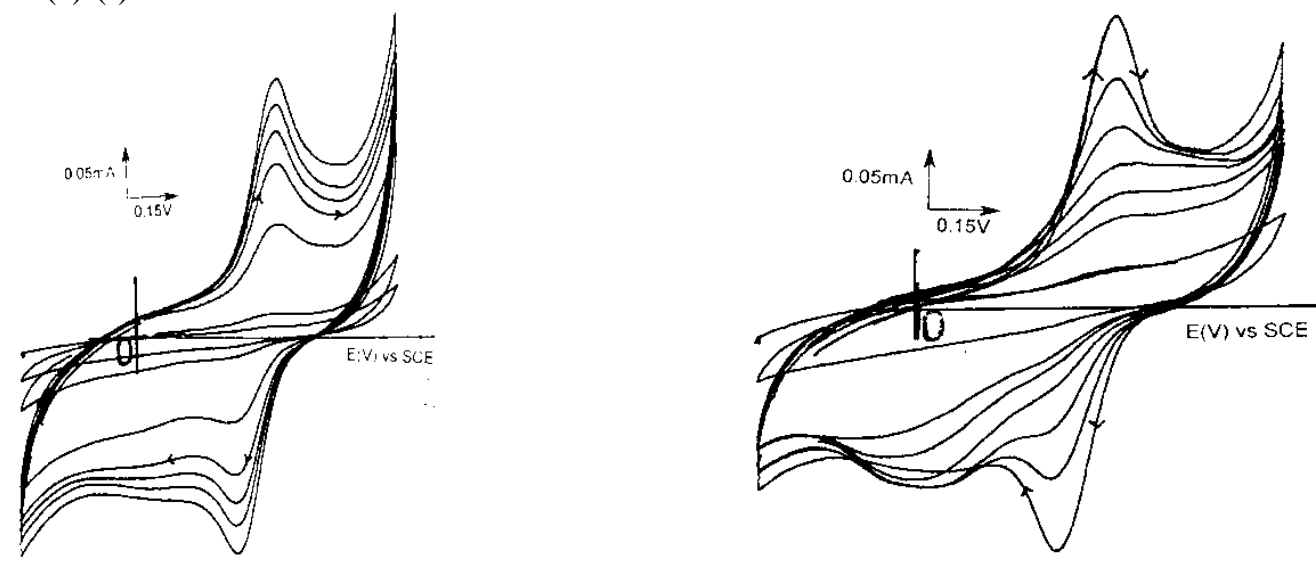

Figure 10a: CV Responses In Case Of Amoxil/Methionine In Water. Figure 10b: CV Responses In Case Of Amoxil/Methionine In Ethanol. 

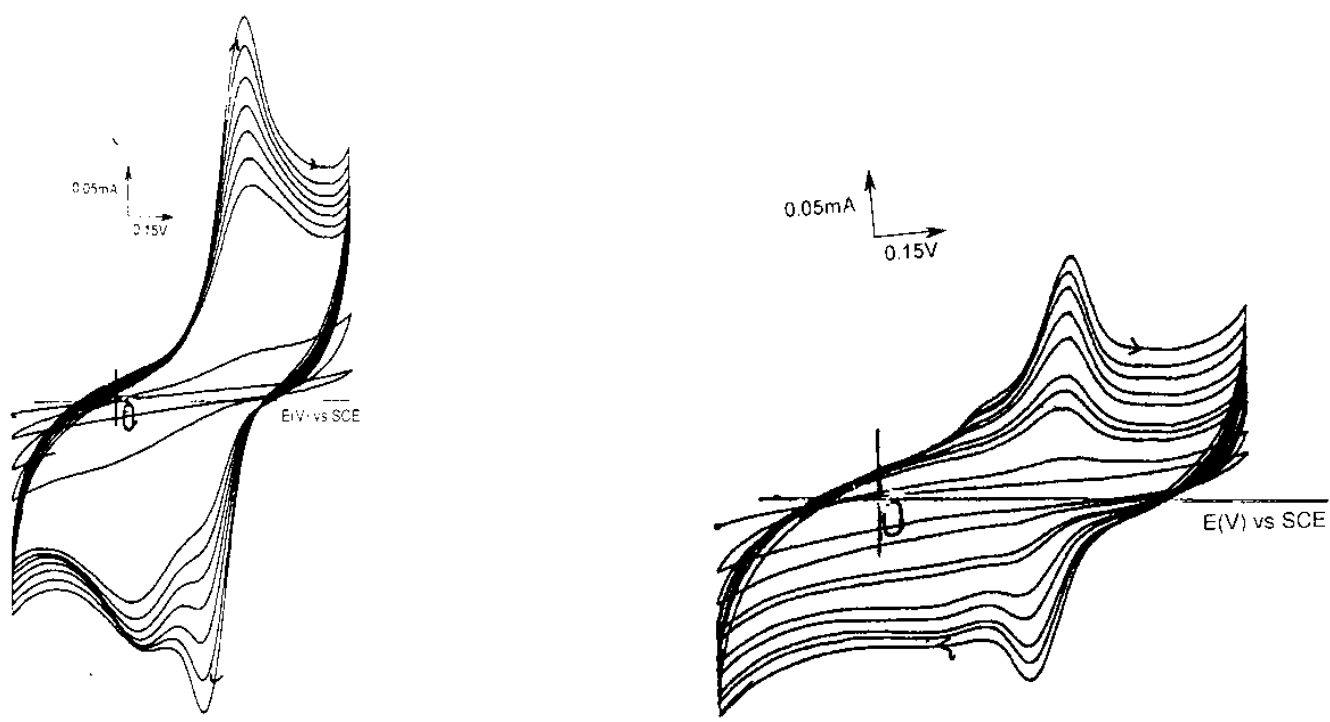

Figure 10c: CV Responses In Case Of Amoxil/LeucineIn Water

Figure 10d: CV Responses In Case Of Amoxil/Leucine In Ethanol.
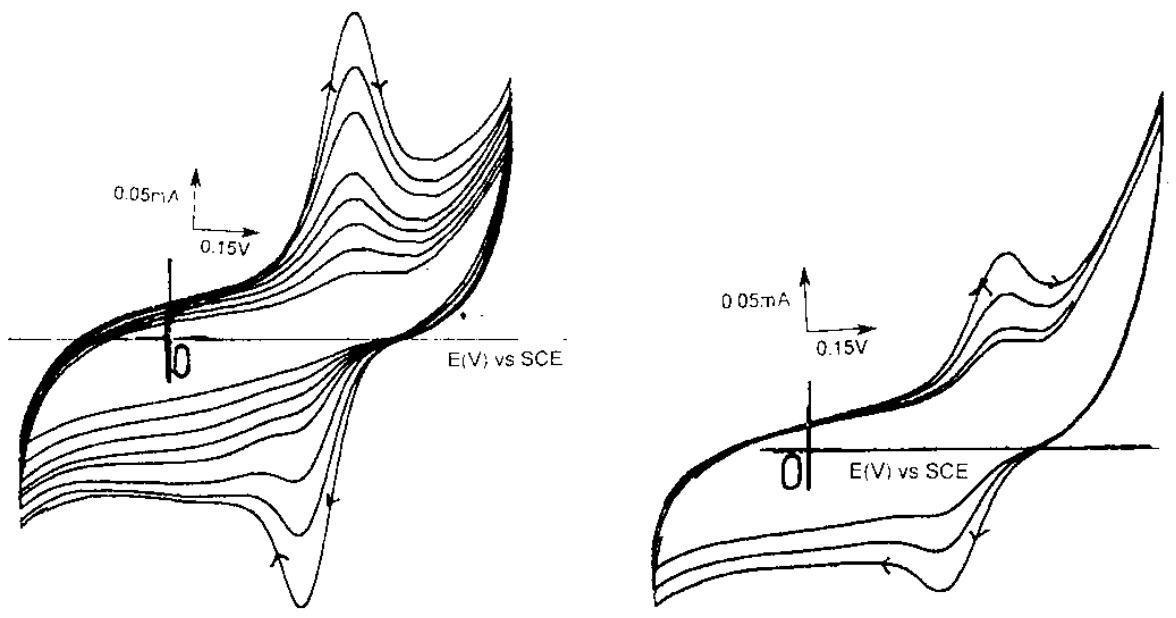

Figure 10e: CV Responses In Case Of Amoxil/Arginine In Water Figure.10f: CV Responses In Case Of Amoxil/Arginine In Ethanol .

The cyclic voltammograms obtained are significantly different, with the one obtained in ethanol showing much morewell defined peaks with oxidation peak occurring at $0.465 \mathrm{v}$ and the reduction peak at $0.345 \mathrm{v}$, while in the case of water, the oxidation peak was broad and poorly defined initially but sharpens with subsequent cycles, and occurred at $0.480 \mathrm{v}$. The reduction peak had a hump at $0.0 \mathrm{v}$ and a well defined peak at $0.330 \mathrm{v}$. These differences in electrochemical responses can be attributed to the differences in the solubility of methionine in the different solvents hence its availability for interaction with amoxil centers.

Similar effects are also observed in the case of leucine and arginine in the two solvents. Since the rate of change of the oxidative peak potential is increasing substantially in the presence of these amino acids, in their preferred solvent in the host matrix suggests the possibility of the amino acids electrocatalysing the amoxil redox process. That, amino-acids do not inhibit the amoxil redox process is significant, as action on the contrary can have serious ramifications given the importance of amino acids in humans and the fact that, amino acids are components of bio-catalysts (enzymes). 


\section{Effect Of Other Drugs On Amoxil}

The effect of hydrocortisone, and paracetamol an analgesic on amoxil was studied. A slurry of amoxil, bentonite and either hydrocortisone or paracetamol were prepared and used to modify the electrode surface. The potential of the working electrode was then cycled from $-0.4 \mathrm{v}$ to $0.9 \mathrm{v}$ at a scan rate of $20 \mathrm{mv} / \mathrm{sec}$ in $1 \mathrm{~m} \mathrm{~h} \mathrm{~h}_{2} \mathrm{SO}_{4}$. The resultant cyclic voltammetric responses are shown in Figures 11a to 11b.

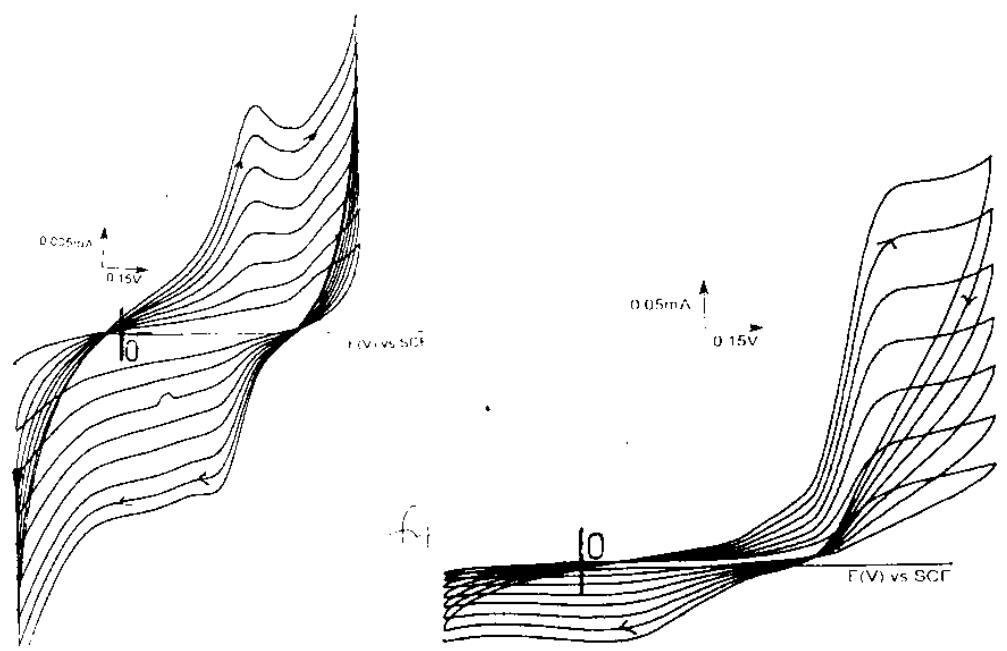

Figure. 11a: CV Obtained In The Case Of The Cases Of Amoxil/Bentonite/ Hydrocortisone Modified Electrode.

Figure 11b: CV Obtained In The Case Of The Cases Of Amoxil/Bentonite/ Paracetamol Modified Electrode.

The effect of hydrocortisone which is a common steroid used in skin ointments was also studied. The cyclic voltammogram obtained (see figure 11a), showed an oxidation peak at $0.480 \mathrm{v}$ and a reduction peak at $0.330 \mathrm{v}$. hydrocortisone does not appear to affect the redox activity of the amoxil.

Paracetamol, a very common analgesic used in conjunction with the antibiotics was also studied. In the case of paracetamol, the cyclic voltammogram obtained is shown Figure 11b. a broad oxidation shoulder is observed at $0.900 \mathrm{v}$ and a broad reduction band spanning the range $0 \mathrm{v}$ to $0.150 \mathrm{v}$ was observed. The redox activity of amoxil was suppressed with a shoulder occurring at $0.525 \mathrm{v}$ with no reduction peak. We propose that, the hydroxyl moeity in paracetamol undergoes chemical reactions with amoxil hence, suppressing the faradaic process in amoxil. Whether this interaction is reproduced at the physiological level remains purely speculative. The discussions of the interactions of amoxil with various chemical substances clearly show that amoxil redox activity is affected. This is informative given that these substances are commonly used together with amoxil either as prescription drug or a past time consumable. It is thus important that, these interactions be taken into consideration assuming that the redox activity determines/ and or plays a role in the therapeutic action of the drug. Those substances which suppress completely the redox activity or slow down redox process can greatly affect overall drug interaction within the body.

\section{U.V Spectrophotometric Analysis:}

It was observed during the use of amoxil that, the solution appeared to change color. It was therefore prudent that these chromic variations be assessed as a function of time for the different solution mixtures, where we dissolved 500mg of amoxil in $0.01 \mathrm{M}, 0.1 \mathrm{M}$, and $1 \mathrm{~m} \mathrm{H}_{2} \mathrm{SO}_{4}$ electrolyte media. UV visible analysis was done on these samples at one hour time intervals. The absorbances measured at a wavelength of $402 \mathrm{~nm}$ were plotted versus time (see Figure 12). 


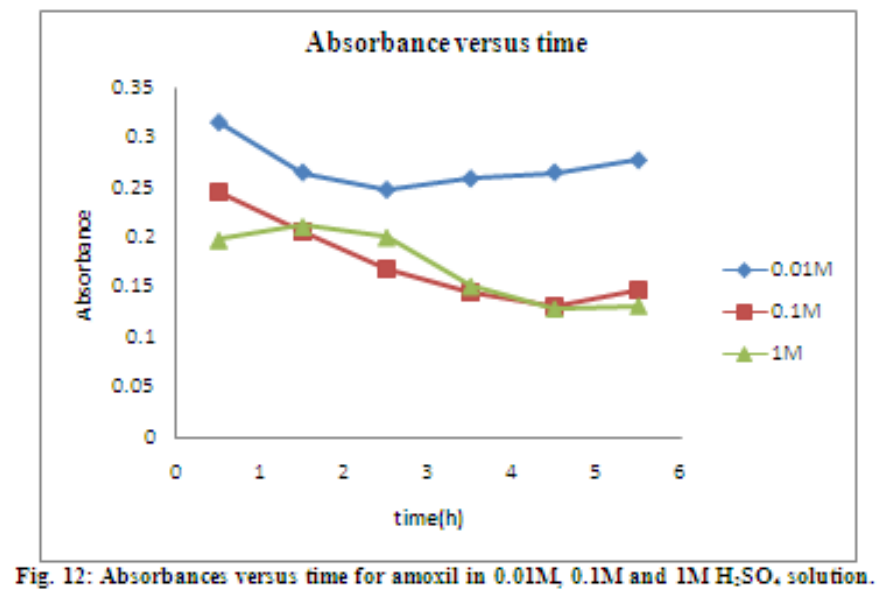

It is observed that, the absorbance decreases with time in samples in containing $1 \mathrm{M}$ and $0.01 \mathrm{M} \mathrm{H}_{2} \mathrm{SO}_{4}$. The absorbance variation with time exhibited in $1 \mathrm{M} \mathrm{H}_{2} \mathrm{SO}_{4}$ is erratic with the absorbance relatively constant followed by a decrease after two hours. This decrease in absorbance can be attributed to changes in the extent of conjugation. This is not surprising given the prescence of the phenolic and lactam groups. These variations can impact the redox process but given the time frame of the changes vis à vis that of electrochemical analysis we do not expect the changes to significantly affect the cyclic voltammetric profiles.

\section{Conclusion:}

The results presented show that carbon graphite working electrode modified using bentonite can be used in the electro-characterization of amoxil using cyclic voltammetry. Its interaction with selected metal ions, amino acids and pharmaceutical preparations leads to the fundamental question as to whether the electrochemical behavior of amoxicillin is stereotyped in its interactions at the physiological level.

\section{References:}

[1]. Blumberg P.M. And Strominger J. L., (1974), Interaction OfPenicillin With The Bacterial Cell: Penicillin - Binding Proteins And Penicillin - Sensitive Enzyme, Bact. Rev. 38, 291.

[2]. Flower RJ And Vane JR, (1972), Inhibition Of Prostaglandin Synthetase In Brain Explains The Anti-Pyretic Activity Of Paracetamol (4-Acetamidophenol), Nature. 240, 410-411

[3]. Forster R.J., (1994), Microelectrodes: New Dimensions In Electrochemistry, Chemical Society Reviews, 94,289-297.

[4]. Fredrickson J. K., Zachara J. M., Balkwill D. L., Kennedy D., Shu-Mei W. Li, Heather M. K., Daly M. Jromine., M. F., And Brockman F. J., (2004), GeomicrobiologyOf High-Level Nuclear Waste-Contaminated Vadose Sediments At The Hanford Site, Appl. Environ. Microbiol.70 (7): 4230-41.

[5]. Orata D.O. And Buttery D.A., (1987), Determination Of Ion Population And Solvent Content As A Function Of Redox State And $\mathrm{Ph}$ In Polyaniline, J.Am. Chem. Soc. 109, 357.

[6]. Orata, D.O AndSegor F. (1999), Bentonite As A Template For Electro- Synthesis Of ThyroxineCatalysis Letter 58, 157- 163.

[7]. Oyama N. And Anson F. C., (1980), Facile Attachment Of Transition Metal Complexes To Graphite Electrodes Coated With Polymer Ligands. Observation And Control Of Metal-Ligand-Coordination Among Reactants Confined To Electrode Surface. J. Am. Chem. Soc. 101, 739

[8]. $\quad$ Parafitt K., (1999), Antimalarials In: Martindale: The Complete Drug Reference. 32 ${ }^{\text {nd }}$ Edn.,Pharmaceutical Press, Pp: $422-442$.

[9]. Reynolds, P.E., (1973), TheBacterial Cell: Major Structures; In Biochemistry Cell Growth, Ed. J. MardelstamAnd McQuillan, $2^{\text {nd }}$ Ed. Pg 63-136. Blackwell, Oxford.

[10]. Riul A. Jr., Gallardo A. M. S., Mello S. V., Bone S., Taylor D. M.AndMattoso L. H. C, (2003),An Electronic Tongue Using Polypyrrole And Polyaniline, Synthetic Metals, 132, 109-116.

[11]. Ro D.K. And Paradise E.M., (2006), Production Of The Antimalarial Drug Precursor Artemisinic Acid In Engineered Yeast. Nature. 440, 940-943.

[12]. Saber R. And Piskin E., (2003), Investigation Of Complexation Of Immobilized Metallothionein With $\quad \mathrm{Zn}(\mathrm{II})$ And Cd(II)Ions Using Piezoelectric Crystals, Biosens. Bioelectron, 18, 1039-1046.

[13]. Savient J.M. And Costa G., (1979), Application Of Electrochemical Techniques To Study Of Chemical Reactions. Ed. Pletcher, T.C., Marcel Dekker, New York, Pp. 480-512.

[14]. Sears C.L, (2005), ADynamic Partnership: Celebrating Our Gut Flora. Anaerobe11 (5): 247-51. 